\title{
Effect of multivitamins on plasma homocysteine in patients with the 5,10 methylenetetrahydrofolate reductase C677T homozygous state
}

\author{
DOMENICO DELL'EDERA ${ }^{1}$, ANDREA TINELLI ${ }^{2}$, GIUSI NATALIA MILAZZO ${ }^{3}$, ANTONIO MALVASI ${ }^{4}$, \\ CARONE DOMENICO $^{5}$, ELENA PACELLA ${ }^{6}$, COMPAGNONI PIERLUIGI $^{7}$, TARANTINO GIUSEPPE $^{1}$, \\ GUIDO MARCELLO $^{8}$, LOMURNO FRANCESCO $^{9}$ and ANNUNZIATA ANNA EPIFANIA ${ }^{10}$ \\ ${ }^{1}$ Unit of Cytogenetic and Molecular Genetics, Madonna delle Grazie Hospital, Matera; \\ ${ }^{2}$ Department of Obstetrics and Gynecology, V. Fazzi Hospital, Lecce; ${ }^{3}$ S'Andrea Hosptital, Sapienza University, Rome; \\ ${ }^{4}$ Department of Obstetrics and Gynecology, Santa Maria Hospital, Bari; ${ }^{5}$ Center of Reproduction and Andrology (CREA), \\ Taranto; ${ }^{6}$ Department of Ophthalmology, Sapienza University, Rome; ${ }^{7}$ Unit of Ophthalmology, Madonna delle Grazie \\ Hospital, Matera; ${ }^{8}$ Laboratory of Hygiene, Department of Biological and Environmental Sciences and Technologies, \\ Faculty of Sciences, University of Salento, Lecce; ${ }^{9}$ Obstetrics and Gynecology Department, Umberto I Hospital, \\ Altamura (BA); ${ }^{10}$ Unit of Clinical Chemistry, Madonna delle Grazie Hospital, Matera, Italy
}

Received February 24, 2013; Accepted June 20, 2013

DOI: $10.3892 / \mathrm{mmr} .2013 .1563$

\begin{abstract}
The role of hyperhomocysteinemia (HHcy) as a cardiovascular risk factor remains a matter of debate, while it correlates with folates, it demonstrates inverse correlation with plasma homocysteine (Hcy) levels and vitamin B12 levels and reduces plasma Hcy levels following supplementation with multivitamins. The purpose of this study was to demonstrate that administering multivitamins at specific doses for 90 days restores normal plasma Hcy levels in women who are homozygous for the thermolabile variant of 5,10 methylenetetrahydrofolate reductase (MTHFR C677T). We enrolled 106 healthy females aged between 30 and 42 years, who were non-smokers, non-vegetarian, normotensive and who had no history of food abuse in the previous months. Only females were enrolled in order to rule out any bias due to the variation in Hcy plasma concentrations between males and females. Patient blood sampling was performed in order to determine plasma Hcy, serum folic acid and vitamin B12 levels. Furthermore, molecular characterization of the C677T polymorphism present in the MTHFR gene, was also performed. The results of this study demonstrated that supplementation with specific multivitamins restores normal plasma Hcy levels, regardless of the MTHFR genotype. Furthermore, it is unnecessary to adminster high doses of folate to reduce plasma Hcy
\end{abstract}

Correspondence to: Dr Domenico Dell'Edera, Unit of Cytogenetic and Molecular Genetics, Madonna delle Grazie Hospital, Contrada Cattedra Ambulante, Matera I-75100, Italy

E-mail: domenicodelledera68@gmail.com

Key words: methylenetetrahydrofolate reductase, hyperhomocysteinemia, multivitamins, folic acid levels, and administering high doses of folate may cause proinflammatory and pro-proliferative effects.

\section{Introduction}

Homocysteine (Hcy) is a sulfur amino acid which is not concerned with the composition of plasmatic proteins, therefore there are no specific DNA base triplets which encode for this amino acid. Hcy is formed as a result of the loss of a methyl group from methionine, an essential amino acid that is introduced in the diet. Hcy is an intermediate product of the metabolic pathway of methionine (1).

Only $1-2 \%$ of total Hcy is free in the plasma, $70-80 \%$ is combined with circulating proteins (mainly albumin) and the remaining section is composed of disulfides, Hcy and a mix of Hcy-cysteine disulfides. Hcy may transform itself through a re-methylation process. This methionine-sparing process is catalyzed by the methionine synthase enzyme (MS), which requires 5-methyltetrahydrofolate (5'-MTHF) as a substrate and cobalamin (vitamin B12) as a cofactor in order to transfer the methyl group of 5-MTHF to Hcy, thereby forming methionine and tetrahydrofolate (THF).

In the liver, where methionine metabolism is particularly active, in addition to the MS there is another enzyme that produces methionine from Hcy by methylation. This enzyme is a methyltransferase that uses betaine or trimethylglycine as a methyl donor (trimethylglycine + Hcy $\rightarrow$ dimethylglycine + methionine).

If methionine is overintroduced, MS is inhibited in order to reduce methyonine synthesis and the transsulfuration pathway is activated by two vitamin B6 (pyridoxine)-dependent enzymes, cystathionine- $\beta$-synthase (CBS) (2) and $\beta$-cistationase, in order to form cystathionine and cysteine respectively (Fig. 1) (3). 

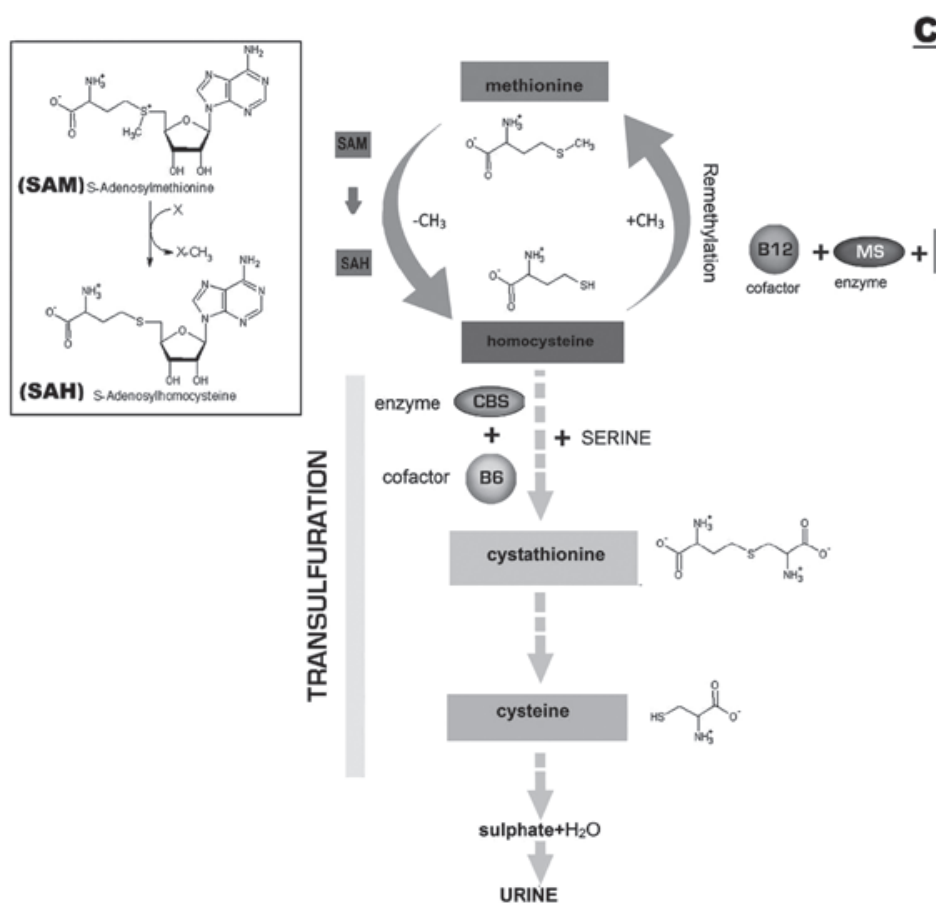

\section{CYCLE OF FOLATE}
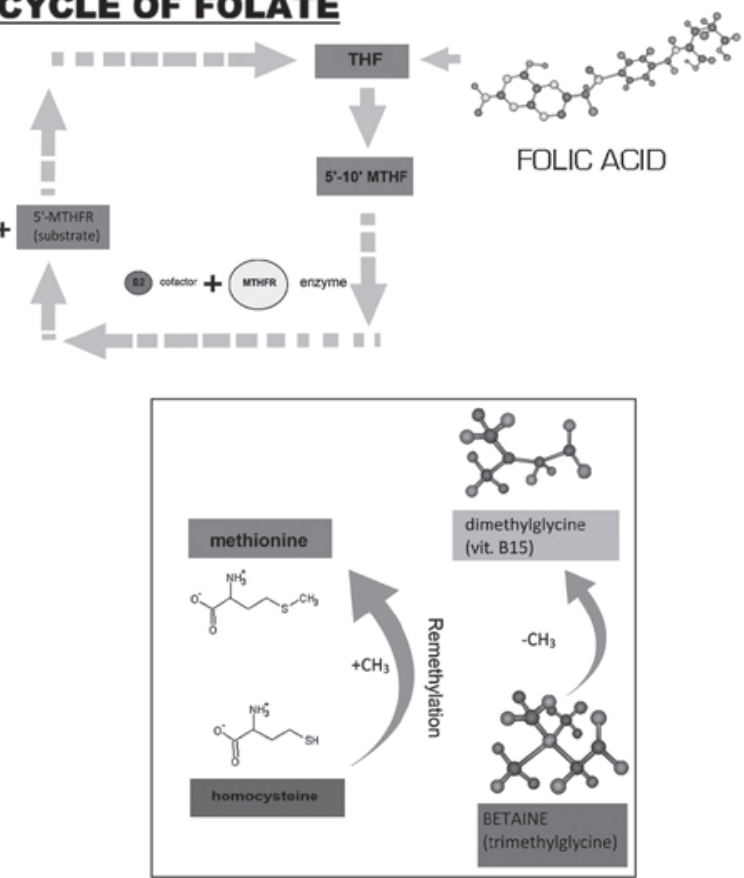

Figure 1. The homocysteine (Hcy)/methionine cycle. The conversion of Hcy to methionine is mediated by the donation of a methyl group from 5-methytetrahydrofolate (5'-MTHF); in the process, tetrahydrofolate (THF) is formed. This reaction is catalyzed by the enzyme methionine synthase (MS) and uses cobalamin (vitamin B12) as a coenzyme. 5'-MTFH is regenerated from THF by using 5',10'-MTHF as an intermediary, completing a folate cycle. Methionine is subsequently used as a methyl $\left(\mathrm{CH}_{3}\right)$ donor in various important metabolic reactions and is converted to Hcy in the process. SAH, S-adenosylhomocysteine; SAM, S-adenosylmethionine.

$\mathrm{N}$-acetyl cysteine (NAC) contributes to the metabolism of Hcy due to the fact that it is a strong antioxidant and the donation of sulfhydryl groups. NAC moves Hcy away from its bond to plasmatic proteins thereby allowing it to be metabolized. Furthermore, due to its antioxidant power, NAC benefits Hcy further by inhibiting the production of reactive oxygen species (ROS) during methionine degradation (4-7). Balancing these metabolic pathways maintains a Hcy plasma concentration of between $5-15 \mu \mathrm{mol} / 1$.

The deficiency, or functional abnormality, of methylenetetrahydrofolate reductase (MTHFR), MS, CBS and/or the lack of their vitamin cofactors results in the defective metabolism of Hcy and therefore it accumulates in the plasma causing mild (15-30 $\mu \mathrm{mol} / \mathrm{l})$ or moderate (30-100 $\mu \mathrm{mol} / \mathrm{l})$ hyperhomocysteinemia (HHcy). A recent meta-analysis of 26 cohort studies has concluded that each $5 \mu \mathrm{mol} / 1$ increase in Hcy levels, compared with the normal values, is associated with a $20 \%$ increase in the risk of a coronary event, regardless of other risk factors (8).

MTHFR catalyzes the conversion of 5,10-MTHF to 5-MTHF, which is necessary in order for MS to convert Hcy to methionine. MTHFR uses the B2 vitamin, riboflavin, as a cofactor. Its key function in the metabolism of Hcy makes this enzyme a hot point in the mechanism which deals with HHcy. The MTHFR gene is polymorphic, with single nucleotide variants at codon 677 in exon $4(\mathrm{C} \rightarrow \mathrm{T})$, which causes an alanine to valine substitution. The codon 677 variant encodes a thermolabile enzyme with reduced activity which increases plasma Hcy levels. Individuals who are homozygous for the codon 677 polymorphism (TT) demonstrate hypomethylation of DNA in peripheral blood leukocytes, this is particularly pronounced when folate levels are low.
The study aimed to demonstrate that the use of multivitamins, administered in specific doses (riboflavin $2.1 \mathrm{mg} / \mathrm{day}$, pyridoxine $2.1 \mathrm{mg} /$ day; cyanocobalamin $3.75 \mu \mathrm{g} /$ day; pteroylmonoglutamic acid $0.3 \mathrm{mg} /$ day; trimethylglycine: $250 \mathrm{mg} /$ day and NAC $300 \mathrm{mg} /$ day) for 90 days, restores normal levels of plasma Hcy, regardless of the MTHFR genotype, in a cohort of females of reproductive age (30-42 years) with a TT (9) and Hcy levels ranging from 18 to $22 \mu \mathrm{mol} / 1$ (10).

This study demonstrates that it is unnecessary to administer high doses of folate to reduce Hcy plasma levels. By contrast, high doses may induce pro-inflammatory and proliferative effects (11). Reduced folate levels are a cardiovascular risk factor and HHcy is a biochemical index of this deficiency (12).

\section{Materials and methods}

Patients. We enrolled 106 healthy females who were admitted to the Madonna delle Grazie Hospital (Matera, Italy) from January, 2012 to June, 2012. The women were aged between 30-42 years and were undergoing premonitory examinations prior to an assisted reproductive technique (ART) cycle. Only females were enrolled in order to rule out any bias due to the varying Hcy plasma concentrations between males and females. All the females enrolled were non-smokers and vegetarian, with no history of food abuse in the previous months and with no history of hypertension. Patient blood sampling was performed to measure Hcy, plasma folic acid and vitamin B12 levels. Furthermore, molecular characterization of the C677T polymorphism of MTHFR gene was also performed. Written informed consent was obtained from the patient for publication 
Table I. Homocysteine, folic acid and B12 vitamin levels found in the two groups of patients.

\begin{tabular}{|c|c|c|c|}
\hline & Group 2 MTHFR 'CT' $(\mathrm{n}=47)$ & Group 3 MTHFR 'CC' $(n=41)$ & P-value \\
\hline $\begin{array}{l}\text { Homocysteinemia }(\mu \mathrm{mol} / \mathrm{l}) \\
\text { Mild HHcy: } 15-30 \\
\text { Moderate HHcy: } 31-100\end{array}$ & $9.3 \pm 3.6$ & $7.3 \pm 1.8$ & \\
\hline $\begin{array}{l}\text { Serum folates } \\
\text { Normal range: } 3,1-20 \mathrm{ng} / \mu 1\end{array}$ & $10.2 \pm 5.9$ & $15.2 \pm 4.9$ & $<0.02$ \\
\hline $\begin{array}{l}\text { B12 vitamin } \\
\text { Normal range: } 211-911 \mathrm{pg} / \mathrm{ml}\end{array}$ & $303.0 \pm 116.1$ & $417.0 \pm 115.0$ & $<0.02$ \\
\hline
\end{tabular}

Values are the means \pm SD. MTHFR, methylenetetrahydrofolate reductase; HHCy, hyperhomocysteinemia.

Table II. Homocysteine, folic acid and B12 vitamin levels found in the two groups of patients.

\begin{tabular}{|c|c|c|c|}
\hline & Group 1 MTHFR 'TT’ $(\mathrm{n}=47)$ & Group 3 MTHFR 'CC' $(n=41)$ & P-value \\
\hline $\begin{array}{l}\text { HHCy }(\mu \mathrm{mol} / \mathrm{l}) \\
\text { Mild HHcy: } 15-30 \\
\text { Moderate HHcy: } 31-100\end{array}$ & $22.0 \pm 15.0$ & $7.3 \pm 1.8$ & $<0.005$ \\
\hline $\begin{array}{l}\text { Serum folates } \\
\text { Normal range: } 3,1-20 \mathrm{ng} / \mu 1\end{array}$ & $4.6 \pm 2.3$ & $15.2 \pm 4.9$ & $<0.001$ \\
\hline $\begin{array}{l}\text { B12 vitamin } \\
\text { Normal range: } 211-911 \mathrm{pg} / \mathrm{ml}\end{array}$ & $342.0 \pm 350.0$ & $417.0 \pm 115.0$ & NS \\
\hline
\end{tabular}

Values are the means \pm SD. MTHFR, methylenetetrahydrofolate reductase; HHCy, hyperhomocysteinemia, NS, not significant.

of this case report and accompanying images. Ethics approval was obtained from the Ethics Committee of the Local Health Unit (LHU; Prot. N. 1122/CE/P in November 5, 2011).

\section{Laboratory examinations}

Assay of Hcy. Blood was collected in the fasting state into tubes containing sodium citrate as an anticoagulant; the tubes were immediately centrifuged at $4^{\circ} \mathrm{C}$ in order to separate the plasma from the corpuscular volume. Plasma samples were frozen at $-20^{\circ} \mathrm{C}$ until required for the Hcy assay. For the Hcy assay the ACL ELITE PRO coagulometer manufactured by Instrumentation Laboratory (Warrington, UK) (latex immunological test for the quantitative determination of total L-Hcy of citrated plasma samples) was used.

Serum folate and vitamin B12 assays. Blood was collected in tubes without an anticoagulant and the tubes were immediately centrifuged in order to separate the serum from the corpuscular volume. Serum samples were frozen at $-20^{\circ} \mathrm{C}$ until they were required for the serum folate and vitamin B12 assays. To do this we used the tool Unicel DXI 800 produced by Beckman Coulter (Miami, FL, USA). The normal ranges for serum folates and vitamin B12 were 3.1-20 $\mathrm{ng} / \mu \mathrm{l}$ and 211-911 pg/ml, respectively.

Molecular probing to examine the genetic polymorphism due to the substitution of cytosine to thymine at nucleotide 677 of the MTHFR enzyme gene. Blood samples collected in EDTA-K3 were used. Molecular analysis required the following steps: i) DNA isolation from $25 \mu 1$ of blood, using the extraction kit from Promega Italy S.r.l. (DNA IQTM System, cod. C6701, Milan, Italy). ii) Amplification of the gene sequences regarding the MTHFR gene. iii) Reverse hybridization on a strip through the use of wild-type and mutant probes and the colorimetric detection of hybrids. iv) Amplifications and the reverse hybridizations on a strip were obtained with the use of commercial kits produced by Nuclear Laser Medicine (cod. AC012, Milan, Italy). Groups were assigned as follows: Group 1 patients were homozygous for the C677T polymorphism in the MTHFR gene (TT); Group 2 patients were heterozygous for the C677T polymorphism in the MTHFR gene (CT); Group 3 patients were wild-type in the C677T polymorphism in the MTHFR gene (CC) (control group).

Statistical analysis. Results are expressed as the means \pm standard deviation (SD) and percentages.

\section{Results and Discussion}

Of the 106 women studied in this report, 16 (15.1\%) from Group 1 were TT, 46 (43.4\%) from Group 2 were heterozygous for the C677T polymorphism in the MTHFR gene (CT), and $44(41.5 \%)$ from Group 3 were wild type in the C677T polymorphism in the MTHFR gene (CC) (control group).

With regards to the Hcy, vitamin B12 and folic acid values found in the three groups are reported in Tables I and II. The 
plasma levels of folate and vitamin B12 were in the normal range for Groups 2 and 3, but the values were significantly higher in Group $3(\mathrm{P}<0.02)$. The average Hcy plasma level for patients in Group 1 was $22 \pm 15 \mu \mathrm{mol} / 1$, while the average Hcy plasma level for Group 3 was $7.9 \pm 2.2 \mu \mathrm{mol} / \mathrm{l}(\mathrm{P}=0.005)$. The average level of plasma folates for Group 1 was $4.6 \pm 2.3 \mathrm{ng} / \mathrm{ml}$, while in Group $3(\mathrm{P}<0.001)$ it was $15.2 \pm 4.9 \mathrm{ng} / \mathrm{ml}$. In Group 1, the mean vitamin B12 serum level was $342 \pm 350 \mathrm{pg} / \mathrm{ml}$ compared with $417.0 \pm 115.0 \mathrm{pg} / \mathrm{ml}$ for Group 3 .

To restore the Hcy plasma levels of patients in Group 1, to the normal range, they were treated with multivitamins in specific doses (riboflavin $2.1 \mathrm{mg} /$ day, pyridoxine $2.1 \mathrm{mg} /$ day; cyanocobalamin $3.75 \mu \mathrm{g} / \mathrm{day}$; pteroylmonoglutamic acid $0.3 \mathrm{mg}$ /day; trimethylglycine: $250 \mathrm{mg}$ /day and NAC $300 \mathrm{mg}$ / day) for 90 days.

Following treatment, the plasma serum Hcy, serum folic acid and vitamin B12 values were $7.4 \pm 1.7 \mathrm{ng} / \mu \mathrm{l}, 8.0 \pm 25 \mathrm{ng} / \mu \mathrm{l}$ and $505 \pm 113 \mathrm{pg} / \mathrm{ml}$, respectively. This demonstrated that using specific doses of multivitamins restores plasma Hcy to normal levels, regardless of the MTHFR genotype, due to the fact that TT patients produce less $\mathrm{CH}_{3}$-THF when folate levels are low. The reduced availability of $\mathrm{CH}_{3}$-THF leads to reduced remethylation of Hcy with a consequent increase in plasma Hcy (HHcy).

However, CC patients are unaffected by folate deficiencies, as the synthesis of $\mathrm{CH}_{3}$-THF is preserved for methylation reactions and for the conversion of Hcy to methionine.

Therefore, the MTHFR C677T genotype does not alter the availability of $\mathrm{CH}_{3}$-THF if there is adequate folate intake. The present study demonstrates that it is unnecessary to administer high doses of folate to reduce Hcy plasma levels and high doses may have pro-inflammatory and pro-proliferative effects (11).

In conclusion, regardless of any doubts as to the role of $\mathrm{HHcy}$ as a pathogenic factor or a direct biochemical marker for more complex metabolic abnormalities, there is evidence that the administration of multivitamins, in appropriate doses, corrects this alteration, with great, and not yet fully explored, benefits for the cardiovascular system. The facility for correcting mild to moderate HHcy creates an opportunity to prevent cardiovascular events. Therefore, measuring Hcy is necessary, particularly for at risk patients (12).

\section{Acknowledgements}

The authors thank 'Association Gian Franco Lupo' (ONLUS: non-profit organization of social utility).

\section{References}

1. Shiraiwa T,Nakagawa K, Kanemoto N, Kinda T and Yamamoto H: Synthesis of optically active homocysteine from methionine and its use in preparing four stereoisomers of cystathionine. Chem Pharm Bull (Tokyo) 50: 1081-1085, 2002

2. de Franchis R, Fermo I, Mazzola G, Sebastio G, Di Minno G, Coppola A, Andria G and D'Angelo A: Contribution of the cystathionine beta-synthase gene (844ins68) polymorphism to the risk of early-onset venous and arterial occlusive disease and of fasting hyperhomocysteinemia. Thromb Haemost 84: 576-582, 2000.

3. Mudd SH, Levy HL and Skovby F: Disorders of transsulfuration. In: The Metabolic and Molecular Bases of Inherited Diseases. Scriver CR, Beaudet AL, Sly WS, Valle D, Childs B, Vogelstein B (eds). McGraw Hill, NY, 88: pp2008-2048, 2001.

4. Hultberg B, Andersson A, Masson P, Larson M and Tunek A: Plasma homocysteine and thiol compound fractions after oral administration of N-acetylcysteine. Scand J Clin Lab Invest 54: 417-422, 1994.

5. Aćimović JM, Stanimirović BD, Todorović N, Jovanović VB and Mandić LM: Influence of the microenvironment of thiol groups in low molecular mass thiols and serum albumin on the reaction with methylglyoxal. Chem Biol Interact 188: 21-30, 2010.

6. Moshal KS, Sen U, Tyagi N, Henderson B, Steed M, Ovechkin AV and Tyagi SC: Regulation of homocysteine-induced MMP-9 by ERK1/2 pathway. Am J Physiol Cell Physiol 290: C883-C891, 2006.

7. Hultberg B: Elimination of high amounts of extracellular homocysteine in human cell lines. Clin Chim Acta 356: 117-124, 2005.

8. Humphrey LL, Fu R, Rogers K, Freeman M and Helfand M: Homocysteine level and coronary heart disease incidence: a systematic review and meta-analysis. Mayo Clin Proc 83: 1203-1212, 2008.

9. Jacques PF, Bostom AG, Williams RR, Ellison RC, Eckfeldt JH, Rosenberg IH, Selhub J and Rozen R: Relation between folate status, a common mutation in methylenetetrahydrofolate reductase, and plasma homocysteine concentrations. Circulation 93: 7-9, 1996.

10. Guttormsen AB, Ueland PM, Nesthus I, Nygård O, Schneede J, Vollset SE and Refsum H: Determinants and vitamin responsiveness of intermediate hyperhomocysteinemia $(>$ or $=$ 40 micromol/liter). The Hordaland Homocysteine Study. J Clin Invest 98: 2174-2183, 1996.

11. Smulders YM and Blom HJ: The homocysteine controversy. J Inherit Metab Dis 34: 93-99, 2011.

12. Quéré I, Perneger TV, Zittoun J, et al: Red blood cell methylfolate and plasma homocysteine as risk factors for venous thromboembolism: a matched case-control study. Lancet 359: 747-752, 2002. 